\title{
A CONSTRUÇÃO SOCIAL DA VADIAGEM NOS DISCURSOS JURÍDICOS DO INÍCIO DA ERA REPUBLICANA
}

Manuela Abath Valença ${ }^{\mathrm{i}}$

Sumário: 1 Introdução. 2 A modernidade, o saber e o outro incivilizado. $2.1 \mathrm{O}$ outro da criminología tradicional: monstros e anormais. $2.2 \mathrm{O}$ perigo das ruas e a vadiagem: o discurso jurídico sobre esse outro incivilizado. 2.3 Os presos da República: mulheres vadias, homens criminosos. 3 Conclusões. Referências.

\begin{abstract}
Resumo
Uma das funções desempenhadas pelas agências do sistema punitivo é a construção social da delinquência, isto é, a identificação do sujeito criminal, a partir das estatísticas criminais e dos discursos sobre o crime e o criminoso. No início da era republicana, a necessidade de se criar uma ética voltada para o trabalho, o aumento da pauperização visível e o medo do que se chamava, nos discursos legislativos, de "ordas de ex-escravos" conduziram a uma criminalização das ilegalidades populares e à construção dos saberes acerca dessa classe perigosa, com grande contribuição da criminologia positivista, mas, também, da dogmática penal. A criminalização da vadiagem é, sem dúvidas, uma expressão
\end{abstract}


desse processo de identificação do crime com a pobreza. Quem eram os vadios? Que risco representavam? Como contê-los? Este trabalho faz um breve resgate dos discursos jurídicos sobre a vadiagem, intentando responder a esses questionamentos.

Palavras-chave: Vadiagem. Criminalização da pobreza. Discurso. Pensamento penal.

\begin{abstract}
One of the functions performed by the agencies of the criminal justice system is the social construction of crime, that is, the identification of the individual from whom we expect the criminal behavior. This task is performed by crime statistics and the speeches about the crime and the criminal. In Brazil, at the beginning of the republican era, the need to create an ethics for work, the increasing of the visible poverty and the fear of what is called, in the legislative speeches, "hordes of ex-slaves" led to a criminalization of popular illegalities and the construction of knowledge about this dangerous class, with great contribution of positivist criminology, but also of the penal thought. The criminalization of vagrancy is undoubtedly an expression of that tendency to identify crime and poverty. Who were identified with the vagrancy? What risk they represented? How to stop them? This work is a brief rescue of legal speech on vagrancy in order to answer these questions.
\end{abstract}

Keywords: Vagrancy. Criminalization of poverty. Speech. Penal thought.

\section{INTRODUÇÃO}

$\mathrm{O}$ discurso sobre o crime é normalmente um discurso sobre o outro, sobre o anormal, sobre o estranho. Tais falas acompanharam as manifestações punitivas, a ponto de Eugenio Raúl Zaffaroni afirmar que a criminologia não é uma invenção do século XIX ${ }^{1}$.

A partir do século XVIII, entretanto, com a formação dos Estados modernos e a pretensão de exercício do monopólio da violência, esses discursos sobre o crime e o criminoso passam a se organizar com vistas ao gerenciamento de uma coletividade e de uma população, utilizando-se de métodos positivistas amplamente permeados por um raciocínio causal.

A formulação foucaultiana sobre o biopoder e a gerência das populações podem nos ajudar a compreender como, a partir de então, os governos se dão conta de que possuem uma "população" a administrar, o que somente seria possível com o conhecimento das leis e normas que regulam este conjunto de pessoas. Surgem então os esforços científicos com esse escopo, sendo fruto desse processo a criação da criminologia como uma ciência.

O projeto moderno ${ }^{2}$ compreende, portanto, não apenas modificações do ponto de vista da estrutura das organizações de repressão, como também a formulação de aparatos de saber necessário ao funcionamento e legitimidade dessas organizações.

No Brasil, porém, garantias processuais penais e uma estrutura organizacional burocrática e racional-legal fundada na legalidade e na isonomia coexistirão com os maus-tratos e os arbítrios cotidianos contra as classes perigosas, as classes populares. O nosso controle e punição, longe da imagem do controle disciplinar das instituições desenhadas por Foucault, assemelham-se ao controle escravista, fundado na proximidade entre os corpos de vigias e vigiados e no recurso à violência física.

Porém, se a prática das instituições não se assemelha ao panoptismo, os saberes o farão. A

${ }^{1}$ ZAFFARONI, Eugênio Raul. Criminologia: Aproximación desde un margen. Bogotá: Editorial Themis, 1988.

${ }^{2}$ Referimo-nos a projeto moderno como aquele em que se determina o monopólio da violência legítima nos órgãos do Estado, organizado em termos de uma burocratização racional-legal, baseada em leis gerais de isonomia e legalidade, e formada por funcionários especializados, dentre outros. 
criminologia tradicional - construída, sobretudo, a partir do saber médico - conformará os tipos sociais perigosos, esclarecendo quem são eles. No geral, aludem às classes populares, avessas à ética do trabalho e à moral burguesa.

Neste trabalho, procuramos analisar quem são os vadios do final do século XIX e início do século XX na literatura jurídica da época. Ao final, apresentamos dados secundários extraídos de uma base do Instituto Brasileiro de Geografia e Estatística (IBGE), que apresenta o perfil da população carcerária de 1907.

\section{A MODERNIDADE, O SABER CIENTÍFI- CO E O OUTRO INCIVILIZADO}

É no século XIX que se organiza, em termos científicos, o saber criminológico. A própria palavra criminologia é usada pela primeira vez em um livro de Raffaele Garofalo, membro da escola positiva italiana, e passa a designar o estudo das causas do crime. Ainda no campo científico, a ideologia racista começa a ganhar espaço, passando a constituir parte integrante desses saberes $^{3}$.

Como dito anteriormente, as formulações sobre o criminoso já existiam, mas possuíam cunho nitidamente teológico. No Período Colonial, as marcas das explorações ibéricas são a escravidão de negros e índios, a destruição dos povos tradicionais e consequentemente de suas culturas (todo o conjunto de expressões simbólicas), e a transferência de estruturas administrativas da metrópole para as colônias, com o fito de garantir o controle social.

Esse controle, fundamental sobretudo para frear as atividades dos insurgentes, funcionou para arrefecer movimentos de resistência e se basearam na eliminação dos então "inimigos".
Para tanto, era preciso encontrar uma forma de justificar tanto a exploração como as possíveis instâncias de controle que, em grande medida, funcionavam com base em lógicas exterminatórias. Assim, as formulações sobre a inferioridade do negro, da inexistência de alma, dentre outras, são comuns.

Como ciência, a criminologia é fruto do movimento cientificista e racista, que se elabora a partir do século XVIII, corroborando com as antigas teses sobre a degeneração de membros das classes populares e negros/as. Como diz Zaffaroni $^{4}$ :

Los 'teólogos' positivistas del siglo XIX (Spencer, Darwin, Morel, Gobineu etc) no hicieron más que justificar la represión y el colonialismo, apuntalando la inferioridade humana del colonizado y del criminalizado com outro sistema de ideas funcionalmente identicos

No Brasil, a recepção de tais pensamentos pode ser visualizada nas teorizações de Nina Rodrigues, médico baiano, que em sua obra "As raças e a responsabilidade penal no Brazil" advoga uma semi-imputabilidade ou inimputabilidade dos membros das "raças inferiores", dotados de comportamentos impulsivos e incivilizados:

O desenvolvimento e a cultura mental pemittem seguramente às raças superiores apreciarem e julgarem as phases por que vai passando a consciencia do direito e do dever nas raças inferiores, e lhes permittem mesmo traçar a marcha que o desenvolvimento dessa consciencia seguiu no seu aperfeiçoamento gradual. ${ }^{5}$

As raças inferiores eram a negra e a indígena. Nina Rodrigues, no esteio de seus contemporâneos ${ }^{6}$, construía a imagem do sujeito criminoso e inferior, dotado de um padrão de desenvolvimento moral e ético inferior aos brancos. Assim, era a inferioridade dessas raças que definiriam o seu caráter degenerado.

\footnotetext{
${ }^{3}$ ARENDT, Hanna. Origens do totalitarismo: antissemitismo, imperialismo, totalitarismo. São Paulo: Companhia das Letras, 2012, p. 235. Hanna Arendt vai situar o século XVIII como o momento do surgimento dessa ideologia racista que, por sua vez, influenciará o desenvolvimento científico positivista do século XIX. Não obstante, é preciso mencionar que a preocupação da autora estava em explicar o surgimento do antissemitismo e da corrida neocolonial à África, no século XIX, quando, em verdade, desde o século XV e XVI, concepções sobre a inferioridade de negros e negras permeavam os discursos religiosos justificadores da escravidão. Cf. DUSSEL, Enrique. 1492: o encobrimento do outro (A origem do "mito da modernidade"). Tradução: Jaime A. Clasen. Petrópolis: Vozes, 1993

${ }^{4}$ ZAFFARONI, Eugênio Raul. Criminologia: Aproximación desde un margen, p. 64.

RODRIGUES, Raymundo Nina. As raças e a responsabilidade penal no Brazil. Rio de Janeiro: Guanabara, 1894, p. 64.

${ }^{6}$ O livro remete às obras de Cesare Lombroso, Enrico Ferri, Raffaele Garofalo e Alexandre de Lacassagne, todos expressões da Escola Positivista na Criminologia.
} 
Em suas primeiras formulações, portanto, a criminologia se empenhava em apresentar condicionantes individuais como a biologia, a fisiologia e a psicologia para explicar o crime. Para tanto, lançavam mão de uma metodologia positivista, como parte do projeto moderno de abandono das explicações mágicas sobre o mundo, como diria Weber ${ }^{7}$. De fato, a ciência moderna afasta-se dos saberes tradicionais, apresentando uma legitimidade própria, assentada na razão, com a adoção de técnicas de controle como os métodos de observação.

$\mathrm{Na}$ América Latina, essa criminologia de matriz europeia foi importada acriticamente para pensar a nossa realidade. A respeito, Del Olmo ${ }^{8}$ pontua:

A criminologia chega à América Latina depois que suas classes dominantes e 'ilustradas' haviam assumido os ditames da ideologia liberal e a filosofia positivista como a melhor via para alcançar a 'ordem e o progresso', mas sobretudo a ordem para acalmar movimentos de guerra civil, caudilhismo etc., e para favorecer a implantação do capitalismo.

Definindo homens e mulheres a partir da lupa europeia de civilização versus barbárie, a criminologia se preocuparia também com os resistentes, trazendo consigo sempre a preocupação de manutenção das coisas como elas eram. Daí porque, em termos de classes perigosas, proletários, anarquistas, negros, "mulheres do cabaré" e índios se uniam.

De fato, quando as constituições e o direito em geral criam a noção de cidadão, o fazem referindo-se a padrões de comportamento 'civilizados', normalmente ligados ao ideário burguês. Assim, são cidadãos os homens, brancos, heterossexuais, chefes de família. O contraponto de tudo isso é também o contraponto da civilização.

Como destaca Gomez'

A invenção da cidadania e a invenção do outro se encontram geneticamente relacionados. Criar a identidade do cidadão moderno na América Latina implicava gerar uma contraluz a partir da qual essa identidade pudesse ser medida e afirmada como tal. A construção do imaginário da 'civilização' exigia necessariamente a produção de sua contraparte: o imaginário da 'barbárie.'

Esse imaginário da barbárie foi, em grande intensidade, construção das produções criminológicas.

\subsection{O outro da criminologia tradicional: mons- tros e anormais}

A criminologia constrói o bárbaro. Depois disso, o que fazer? As funcionalidades em torno da construção desse ser inferior estariam, segundo Foucault, diretamente relacionadas a uma nova economia política da punição demandada pela sociedade capitalista industrial. O grande trunfo dos aparelhos de disciplina, dentre os quais a prisão, operados a partir de saberes como a criminologia, seria o de disciplinar corpos, tornando-os dóceis e funcionais à economia capitalista.

Para Foucault, a formação de uma "sociedade disciplinar" a partir do início do século XIX pode ser evidenciada pela reforma nos aparelhos judiciais e penais. O clássico brocardo "não há crime sem lei anterior que o preveja" consagra uma separação entre falta moral e religiosa e delito, procurando construir uma noção laica de crime e do próprio criminoso, identificado, no estilo da Escola Clássica, como o sujeito que, dotado de livre-arbítrio, opta pelo crime. A punição poderia estar na eliminação e no afastamento desses inimigos sociais ${ }^{10}$.

Porém, as práticas punitivas que efetivamente se desenvolveram nessa época tiveram, segundo Foucault, outro objetivo: a correção. E concluiu: "A penalidade no século XIX, de maneira cada vez mais insistente, tem em vista menos a defesa geral da sociedade que o controle e a reforma psicológica e moral das atitudes e dos comportamentos dos indivíduos.".

\footnotetext{
${ }^{7}$ WEBER, Max. Ensaios de sociologia. Rio de Janeiro: Zahar, 1963.

${ }^{8}$ DEL OLMO, Rosa. A América Latina e sua criminologia. Rio de Janeiro: Revan, 2004, p. 162.

${ }^{9}$ GOMEZ, 2005, p. 175-176.

${ }^{10}$ FOUCAULT, Michel. A verdade e as formas jurídicas. Rio de Janeiro: Nau Editora, 2009, p. 81-82.

${ }^{11}$ FOUCAULT, Michel. A verdade e as formas jurídicas, p. 85.
} 
Desse modo, as punições adquiriram um formato de disciplinamento e reforma dos indivíduos, sendo a prisão a consagração deste modelo ${ }^{12}$. Para o autor:

A prisão, peça essencial no conjunto das punições, marca certamente um momento importante na história da justiça penal: seu acesso à 'humanidade'. Mas também um momento importante na história desses mecanismos disciplinares que o novo poder de classe estava desenvolvendo: o momento em que aqueles colonizam a instituição judiciária. [...] ao fazer da detenção a pena por excelência, ela introduz processos de dominação característicos de um tipo particular de poder. Uma justiça que se diz 'igual', um aparelho judiciário que se pretende 'autônomo', mas que é investido pelas assimetrias das sujeições disciplinares, tal é a conjunção do nascimento da prisão, 'pensa das sociedades civilizadas'. ${ }^{13}$

Para além do ato, essa nova organização da justiça penal está formatada para lidar com o indivíduo enquanto um sujeito dotado de características pessoais, psicológicas e biológicas que o tornam um ser voltado ou não a prática de ilícitos. A noção de periculosidade se torna central, determinando a compreensão do sujeito "ao nível de suas virtualidades e não ao nível de seus atos". ${ }^{14}$

Desse modo, a técnica processual de perquirição da verdade típica da Idade Média - o inquérito -, a partir do qual se buscava a reconstituição dos fatos passados, da aquisição da memória sobre o ato criminoso, vai dar lugar a outra forma de busca da verdade: o exame. $\mathrm{O}$ exame não objetiva compreender apenas como se passaram os fatos, mas quem é esse sujeito que os praticou. O exame promove um saber "que tem agora por característica não mais determinar se alguma coisa se passou ou não, mas determinar se um indivíduo se conduz ou não como deve, conforme ou não à regra, se progride ou não etc."15.

O exame psiquiátrico é o principal documento para alcançar essa finalidade. Ele será capaz de deslocar a intervenção punitiva do ato para o sujeito e, ao mesmo tempo, definir positivamente o sujeito delinquente ${ }^{16}$. Ademais, a cientificidade de que estaria dotado esse tipo de investigação cobriu de legitimidade os laudos psiquiátricos, a ponto de se tornarem fonte privilegiada para a adoção das decisões judiciais.

Assim, o exame dará à justiça o subsídio necessário para intervir sobre o ser delinquente e, ao mesmo tempo, identificará os elementos que o tornaram delinquente e perigoso. Nas palavras de Foucault17, "o exame tem por função dobrar o autor, responsável ou não, do crime, com um sujeito delinquente que será objeto de uma tecnologia específica”.

Quem foi esse sujeito? Que elementos foram fundamentais para torná-lo desviante? Nas conferências organizadas na publicação Os anormais, Foucault apresentará alguns processos judiciais e a maneira como a formação da verdade processual articulou-se aos conteúdos desses exames. Se o ato é menos importante que o sujeito delinquente, o exame valorará elementos extrapenais. Esses documentos apontam para as "faltas sem infração" ou "defeitos sem ilegalidade", formadores da personalidade desviante. Neles, aspectos como infância, desejos sexuais, relações familiares, dentre outros, serão articulados ao ato, mas, sobretudo, ao conceito de criminoso.

A personalidade desviante é o objeto central da elaboração do exame e, por meio dele, busca-se descobri-la e descrevê-la. Como se percebe, esse conhecimento médico está plenamente articulado aos processos de poder - não apenas aquele emanado das agências estatais -, na medida em que o saber sobre o sujeito delinquente oferece as justificativas necessárias à construção de aparatos de controle formal e informal. $\mathrm{O}$ delinquente é alguém sempre pronto a praticar uma ilegalidade. Ele precisa, portanto, ser controlado e, quando possível, domesticado.

Essa é a interpretação da "sociedade discipli-

\footnotetext{
${ }^{12}$ FOUCAULT, Michel. Vigiar e punir. 35. ed. Petrópolis: Vozes, 2008, p. 195.

${ }^{13}$ FOUCAULT, Michel. Vigiar e punir, p. 195

${ }^{14}$ FOUCAULT, Michel. A verdade e as formas jurídicas, p. 85.

${ }^{15}$ FOUCAULT, Michel. A verdade e as formas jurídicas, p. 88.

${ }^{16}$ FOUCAULT, Michel. Os anormais. São Paulo: Martins Fontes, 2013, p. 18-19.

${ }^{17}$ FOUCAULT, Michel. Os anormais, p. 19.
} 
nar" ao nível do indivíduo. Mas, segundo Foucault, as técnicas de controle não se desenvolvem apenas sobre o "homem-corpo", mas também sobre o que o autor referirá como "homem vivo", "homem espécie":

Depois de uma primeira tomada de poder sobre o corpo que se fez consoante o modo de individualização, temos uma segunda tomada de poder que, por sua vez, não é individualizante mas que é massificante, se vocês quiserem, que se faz em direção não do homem-corpo, mas do homem-espécie. ${ }^{18}$

Esse biopoder, poder sobre a coletividade dos indivíduos, sobre a massa de seres humanos, estará atento aos mecanismos de mortalidade, natalidade, preservação da espécie, higiene pública, dentre outros. A noção de "população" passa a integrar as instâncias de poder. Os governos passam a gerir essa população, tendo como principal escopo a sua preservação.

Como falamos acima, é nesse contexto que o discurso criminológico científico surge. A função desse saber será a de identificar o anormal, o monstro, o indivíduo perigoso e, para tanto, tipificá-lo como corrigível ou incorrigível. Os corrigíveis seriam submetidos a aparelhos disciplinares, ao passo que os incorrigíveis, porque daninhos ao desenvolvimento da sociedade, poderiam ser simplesmente eliminados.

A técnica do exame, tão essencial à identificação pessoal do perigo, poderá ser útil não apenas às instituições disciplinares, mas também à preservação das populações, ao identificar os indivíduos indesejados, incapazes de serem mantidos na vida social.

Leituras mais contextualizadas, no Brasil, sobre a obra de Foucault sugerem que a prisão não dispôs de técnicas de disciplina eficientes para a domesticação dos corpos, mormente onde o cárcere sempre constituiu um espaço de depósito de indesejados, jogados um tanto à própria sorte. Mais provavelmente, portanto, um espaço de morte que de disciplina ${ }^{19}$.

Porém, a identificação do tipo social do criminoso, como dissemos, é fundamental ao controle social. No século XIX, marcado por sublevações sociais, abolição da escravidão e modificação das dinâmicas das cidades, o controle do refugo humano que passa a vaguear nas cidades se torna fundamental. A construção do tipo social perigoso do vagabundo ganha, então, suma importância.

\subsection{O perigo das ruas e a vadiagem: o discurso jurídico sobre esse outro incivilizado}

O Código Penal de 1890 vem sendo apontado como um dos principais instrumentos legais para propiciar o controle social das classes populares e afirmação de uma ética do trabalho.

O ideal de civilização pressupunha integração a uma nova ordem produtiva onde os escravos não faziam mais parte da cena. O mundo do trabalho com sua nova lógica de controle deveria absorver a grande massa de libertos, transformando-os em trabalhadores livres. Era então preciso dar positividade ao conceito de trabalho - que até então era entendido como coisa de escravo e, por isso, aviltante - conferindo-lhe um sentido enobrecedor, vinculá-lo à honra, à virtude e à liberdade..$^{20}$

Os que se opunham a essa ética do trabalho seriam considerados perigosos. $\mathrm{Ou}$, em poucas palavras: enquanto o trabalho é a lei suprema da sociedade, a ociosidade é uma ameaça à ordem²1.

No Código Criminal do Império, de 1830, a vadiagem era crime que consistia em "não tomar qualquer pessoa uma ocupação honesta e útil de que pudesse subsistir, depois de advertido pelo juiz de paz, não tendo rendas sufficientes”. Em 1890, com a aprovação do novo Código Penal, a vadiagem passou a ter outra redação:

Art. 399. Deixar de exercitar profissão, officio, ou qualquer mister em que ganhe a vida, não possuindo meios

\footnotetext{
${ }^{18}$ FOUCAULT, Michel. Em defesa da sociedade. São Paulo: Martins Fontes, 2005, p. 289.

${ }^{19}$ KOERNER, Andrei. Punição, disciplina e pensamento penal no Brasil do século XIX. Lua Nova, n. 68, p. 205-242, 2006; SANTOS, Myriam Sepúlveda. A prisão dos ébrios, capoeiras e vagabundos no início da Era Republicana. Topoi, v. 5, n. 8, p. 138-169, jan.-jun. 2004.

${ }^{20}$ GARZONI, Lerice de Castro. Nas fronteiras do não-trabalho: trabalhadores pobres e as definições de vadiagem no início do século XX. Revista Mundo do Trabalho, v. 1, 2009, p. 32.

${ }^{21}$ CHALHOUB, Sidney. Trabalho, lar e botequim: o cotidiano dos trabalhadores no Rio de Janeiro da Belle Époque. Campinas: Ed. da Unicamp, 2001, p. 46.
} 
de subsistencia e domicilio certo em que habite; prover a subsistencia por meio de occupação prohibida por lei, ou manifestamente offensiva da moral e dos bons costumes:

Pena - de prisão cellular por quinze a trinta dias. $\$ 1^{\circ}$ Pela mesma sentença que condemnar o infractor como vadio, ou vagabundo, será elle obrigado a assignar termo de tomar occupação dentro de 15 dias, contados do cumprimento da pena.

$\$ 2^{\circ}$ Os maiores de 14 annos serão recolhidos a estabelecimentos disciplinares industriaes, onde poderão ser conservados até a idade de 21 annos.

Em 1893, o Decreto Legislativo n. 145, de 11 de julho, passou a prever outro conceito para a vadiagem, compreendendo:

homem ou mulher, maior de 14 annos, não esteja sujeito ao poder paterno, ou sob direção de tutores ou curadores; que não tenha meios de subsistência por fortuna própria ou profissão, arte, officio, occupação, legal e honesta em que ganhe a vida; que vagueie pela cidade na ociosidade. ${ }^{22}$

Com a punição da vadiagem, o que se pretendia evitar era a prática de crimes de maior gravidade. A contravenção não era vista como uma infração que, por si só, provocava lesões a bens jurídicos, mas como atitude que denotava o perigo do sujeito que, voluntariamente, dedicava-se ao ócio, a vaguear pelas ruas ou a ocupações ilegais e imorais. A punição era antecipada, objetivando-se conter os elementos perigosos. Embora houvesse um caráter moralizante na punição dessas condutas, fundamental é compreender que, na esteira das concepções criminológicas da época, o vadio era entendido como alguém dotado de periculosidade.

Haverá, nas definições doutrinárias sobre o tema, mas também na prática das agências de controle, sobretudo a polícia, uma estreita relação entre classes perigosas e classes populares.

Nesse sentido, posicionava-se Soares ${ }^{23}$ : "A vadiagem é, como diz Silva Ferrão, menos um facto criminoso em si mesmo do que um modo de existência social perigoso que o legislador quis reprimir.. ${ }^{24}$ E complementava:

A vadiagem como parasitismo social e anti social é um fenômeno individual, social e econômico, punível quando anti social, isto é, quando pode constituir germen ou terreno preparado para os crimes, ou quando affecta os interesses da ordem econômica ou da segurança social

Araújo também concebia a criminalização da vadiagem como um mecanismo para evitar delitos mais graves, que a vida nas ruas poderia proporcionar. Nas suas palavras:

Si por um lado as infrações que representam as contravenções não têm a gravidade que apresentam os crimes, por outro lado são fatos cuja repressão, embora mais branda quanto á penalidade, muito importa a um bom systema penal, desde que têm um effeito pratico, sinão prevenir efficazmente os crimes de natureza correspondente, torna-los mais raros pelo effeito da intimidação causada pela punição dos factos mais ligeiros. $^{25}$

A indicação do perigo e a pretensão de normalização desses sujeitos estavam próximas no que toca ao discurso. Tanto é assim que, para reprimir a vadiagem, prescrevia-se a internação dos vadios em casas de correção, onde poderiam aprender um ofício lícito e, ao mesmo tempo, incorporar a ética do trabalho.

É interessante, a respeito, a fala do juiz de direito José Burle de Figueiredo:

A sociedade tem incontestavelmente, o direito de estabelecer medidas de preservação social, ainda mesmo coercitivas, contra mendigos e vagabundos. Consideremos, porém, que essas medidas de defesa correspondem a uma ação puramente preventiva, com o fim de reeducar e adaptar ao meio social, os indivíduos que, em virtude de suas condições de vida, se presumam perigosos, conquanto ainda não tenham delinquido ou dado provas pessoaes de uma periculosidade latente e, por isso, a tendência actual da doutrina, já corporificada alias, nas legislações da Belgica, Suissa, Noruega, Suecia, Dinamarca e Hollanda, não mais considera a vagabundagem como um delito, mas como um estado de facto, julgado perigoso, e contra o qual o poder público

\footnotetext{
${ }^{22}$ SIQUEIRA, Geraldino. Direito penal brasileiro. Brasília: Senado Federal, Conselho Editorial, 2003. v. 2, p. 920.

${ }^{23}$ SOARES, Oscar Macedo. [1910] Código Penal da República dos Estados Unidos do Brasil commentado. Brasília: Senado Federal, Superior Tribunal de Justiça, 2004. v. 6. (Coleção História do Direito), p. 797.

${ }^{24}$ SOARES, Oscar Macedo. [1910] Código Penal da República dos Estados Unidos do Brasil commentado, p. 797.

${ }^{25}$ ARAÚJO, João Vieira de. Código Penal comentado teórica e praticamente. Rio de Janeiro, São Paulo: LAEMMERT \& C. Editores, 1896, p. 429.
} 
tem o dever de estabelecer medidas de cautela, organizando administrativamente a assistência contra essa chaga social e ainda administrativamente recolhendo todos esses indivíduos quer doentes ou inválidos, quer os presumidamente perigosos, a estabelecimentos do Estado a hospitaes Moraes. ${ }^{26}$

Para Figueiredo ${ }^{27}$, age com erro a polícia quando recolhe e detém, como vadios, pessoas que estão simplesmente sem ocupação nas ruas. Para ele, a legítima intervenção estatal é aquela que procura "curar" esses delinquentes, dando-lhes oportunidade de desenvolver uma vida voltada para o trabalho. Desenvolve-se o típico pensamento correcional que advoga uma missão regeneradora e normalizadora das instituições de controle estatal, ou, em termos foucaultianos, disciplinadora.

Há de se frisar ainda que, no discurso sobre os vagabundos, as mulheres são representadas pelas prostitutas. Embora não se punisse a prostituição, a concepção de que este trabalho era imoral enquadrava a conduta na contravenção de vadiagem.

Rago $^{28}$ comenta que:

O retrato da mulher pública é construído em oposição ao da mulher honesta, casada e boa mãe, laboriosa, fiel e dessexualizada. A prostituta construída pelo discurso médico simboliza a negação dos valores dominantes, 'pária da sociedade' que ameaça subverter a boa ordem do mundo masculino.

Se, por outro lado, tolera-se a prostituição para a satisfação dos "incansáveis desejos sexuais masculinos", que jamais poderiam ser plenamente satisfeitos por suas esposas-mães família, à prostituição era possível recorrer. Porém, essa atividade não poderia ser realizada à vista das boas moças. Os prostíbulos deveriam ser localizados em locais distantes - leia-se: na periferia e as prostitutas não poderiam circular de forma ostensiva.
A autora também relata que: "A prostituição pública suscitou desde o final do século XIX a intervenção das autoridades policiais, como forma de reprimir e de 'prevenir toda ofensa à moral e aos bons costumes', como dizia o delegado Cândido Motta.. ${ }^{29}$

Soares ${ }^{30}$ cita uma determinação expedida por delegado de polícia do Rio de Janeiro a qual determinava:

a) que intimem a vir a esta Delegacia qualquer meretriz, notoriamente conhecida como tal, que fôr vista em exhibição nas portas ou janellas; b) que fação prender aquellas que, nas ruas ou lugares frequentados pelo publico, demonstrem de modo inequívoco, a escandalosa e reprovada ocupação a que habitualmente se entregarão.

Em seguida conclui:

Se todos os delegados providenciassem no mesmo sentido e, sobretudo, se as ordens fossem cumpridas meticulosamente pelos subalternos, em algumas ruas desta cidade não se exhibiriam os quadros escandalosos que tanto ofendem á moral publica e aos bons constumes. ${ }^{31}$

Também Siqueira ${ }^{32}$, ao referir-se à vadiagem por exercício de ocupações ilegais e imorais, anota que "se tem profissão, arte, officio ou ocupação, é preciso que seja honesta e legal e, além disso, exercida habitualmente. Não estaria neste caso, por ilegal, a occupação do jogador, proxeneta ou caften, etc.; por deshonesta, a da prostituta, etc.".

Essas acepções no pensamento jurídico penal sobre a vadiagem ajudam a interpretar o porquê de, nos primeiros anos do século passado, termos tantas mulheres presas por esta contravenção.

Em trabalho sobre as Colônias correcionais instaladas no Rio de Janeiro entre 1894 e 1903, Santos ${ }^{33}$ observa que, em seus interiores, onde mulheres, homens e crianças se reuniam, exis-

\footnotetext{
${ }^{26}$ FIGUEIREDO, José Burle de. A contravenção de vadiagem. Rio de Janeiro: [s.n.], 1924, p. 12.

${ }^{27}$ FIGUEIREDO, José Burle de. A contravenção de vadiagem.

${ }^{28}$ RAGO, Margareth. Do cabaré ao lar: a utopia da cidade disciplinar e a resistência anarquista. 4. ed. São Paulo, Rio de Janeiro: Paz e Terra, 2014 , p. 122.

${ }^{29}$ RAGO, Margareth. Do cabaré ao lar: a utopia da cidade disciplinar e a resistência anarquista, p. 122.

${ }^{30}$ SOARES, Oscar Macedo. [1910] Código Penal da República dos Estados Unidos do Brasil commentado, p. 799.

${ }^{31}$ SOARES, Oscar Macedo. [1910] Código Penal da República dos Estados Unidos do Brasil commentado, p. 799.

${ }^{32}$ SIQUEIRA, Geraldino. Direito penal brasileiro, p. 921.

${ }^{33}$ SANTOS, Myriam Sepúlveda. A prisão dos ébrios, capoeiras e vagabundos no início da Era Republicana. Topoi, v. 5, n. 8, p. 138-169, jan.-jun. 2004, p. 157.
} 
tiam os tipos "homens ébrios e vadios" e as "mulheres vagabundas".

Podemos deduzir que as prostitutas eram enviadas à Colônia porque tinham ocupações que eram 'manifestamente ofensivas da moral e dos bons costumes ou porque 'quebravam o termo de bem viver', termo ainda mantido nos relatórios ministeriais desse período [...] Os homens, fossem eles condenados por serem bêbados, mendigos, vadios, capoeiras e ladrões, eram citados no relatório como sendo 'homens' ou detentos do 'sexo masculino'. As mulheres, entretanto, não eram mulheres simplesmente, elas eram 'mulheres vagabundas'.

Assim, homens ociosos e antissociais e mulheres vagabundas compunham parte da imagem do perigo social no final do século XIX.

\subsection{Os presos da República: mulheres vadias, homens criminosos}

Os dados aqui apresentados foram extraídos da base do IBGE, intitulada: "O Brasil no século XX”. Embora possam ser informações precárias, dada a dificuldade de se criar um sistema de controle desses dados, os números apresentados dialogam com os trabalhos citados antes, demonstrando claramente que a população de presos por contravenções era basicamente compreendida de vadios.

Em 1907, a população prisional brasileira era de 1.449 pessoas, sendo 101 mulheres e 1.348 homens. O percentual de mulheres presas, no total da massa carcerária, é semelhante ao de hoje, girando em torno de 6,9\%.

Dos homens presos, 8,9\% cumpriam pena por prática de contravenções e $91,1 \%$ por crimes. Entre as mulheres, essa proporção inverte-se: $82,1 \%$ delas estavam recolhidas pela prática de contravenções, ao passo que $17,9 \%$, pela de crimes. Assim, tínhamos basicamente uma população de mulheres contraventoras e homens criminosos.
Dentre os crimes, a distribuição era a seguinte:

\begin{tabular}{|l|c|c|c|c|}
\hline Sexo/tipo penal & Homicídio & $\begin{array}{c}\text { Tentativa de } \\
\text { homicídio }\end{array}$ & $\begin{array}{c}\text { Lesões } \\
\text { corporais }\end{array}$ & $\begin{array}{c}\text { Violência } \\
\text { sexual }\end{array}$ \\
\hline Mulheres & 9 & - & 5 & - \\
\hline Homens & 569 & 28 & 257 & 56 \\
\hline
\end{tabular}

Fonte: IBGE- Estatísticas do Século $\mathrm{XX}^{34}$ Elaborado pela autora.

\begin{tabular}{|l|c|c|c|}
\hline Sexo/contravenção & Mendicidade & Vadiagem & $\begin{array}{c}\text { Outras } \\
\text { contravenções }\end{array}$ \\
\hline Mulheres & 3 & 80 & - \\
\hline Homens & 3 & 115 & 3 \\
\hline Total & 6 & 195 & 3 \\
\hline
\end{tabular}

Fonte: IBGE- Estatísticas do Século XX ${ }^{35}$

Elaborado pela autora.

Como se observa, em 1907, as mulheres correspondiam a $41,02 \%$ das pessoas presas por contravenção de vadiagem. Aliás, praticamente todas elas cumpriam pena por esse tipo de contravenção.

Esse dado é bastante curioso, já que, tradicionalmente, as mulheres representam uma minoria na população carcerária. Entretanto, como mencionamos acima, o tipo contravencional de vadiagem se referia a atividades "imorais" e o discurso jurídico associava a vadiagem à atividade de prostituição. Essas mulheres do cabaré, nas ruas e longe do lar, pareciam constituir, de fato, uma preocupação central do controle social.

\section{CONCLUSÕES}

A ciência ganhou pretensões de validade universal com o desenvolvimento da modernidade. No campo da criminologia, esse tipo de discurso, sempre preocupado com a identificação do

\footnotetext{
${ }^{34}$ INSTITUTO BRASILEIRO DE GEOGRAFIA E ESTATÍ́STICA (IBGE). Estatísticas do século XX. [s.d.]. Disponível em: <http://seculoxx.ibge.gov.br/ populacionais-sociais-politicas-e-culturais $>$. Acesso em: 19 set. 2014.

${ }^{35}$ INSTITUTO BRASILEIRO DE GEOGRAFIA E ESTATÍSTICA (IBGE). Estatísticas do século XX. [s.d.]. Disponível em: <http://seculoxx.ibge.gov.br/ populacionais-sociais-politicas-e-culturais>. Acesso em: 19 set. 2014.
} 
sujeito criminoso, deixou de lado fundamentações religiosas para passar a associar as classes perigosas às classes populares a partir de achados científicos.

A importação dessa criminologia de matriz europeia para a América Latina apenas reforçou o histórico de estratificação social e racial que, desde o século XVI, vinha perpetuando-se a partir da oposição civilização versus barbárie imposta pelo mito da modernidade.

Assim, no século XIX, os achados científicos apontam pobres e negros como os sujeitos tipicamente criminais, justificando o controle social sobre essa população.

A criação do tipo penal de vadiagem é expressão nítida desse movimento, que se sustentou no ideal disciplinador dos teóricos europeus e na criação de tipos sociais perigosos, sobre quem deveriam recair as tarefas de normalização ou, no limite, de eliminação.

Na prática, pouco se viu do projeto normalizador no interior de Casas de Correção. Mas a associação entre classes perigosas e classes populares se fez de tal forma que, até a atualidade, nutre a atuação do Sistema de Justiça Criminal, a ponto de Dussel ${ }^{36}$ identificar nesses marginais de hoje os rostos desses outros encobertos há séculos.

\section{REFERÊNCIAS}

ARAÚJO, João Vieira de. Código Penal comentado teórica e praticamente. Rio de Janeiro, São Paulo: LAEMMERT \& C. Editores, 1896.

ARENDT, Hanna. Origens do totalitarismo: antissemitismo, imperialismo, totalitarismo. São Paulo: Companhia das Letras, 2012.

CASTRO-GÓMEZ, Santiago. Ciências sociais, violência epistêmica e o problema da "invenção do outro". LANDER, Edgardo (Org.). A colonialidade do saber: eurocentrismo e ciências sociais. Perspectivas latino-americanas. Buenos Aires, CLACSO, 2005.
CHALHOUB, Sidney. Trabalho, lar e botequim: o cotidiano dos trabalhadores no Rio de Janeiro da Belle Époque. Campinas: Ed. da Unicamp, 2001.

DEL OLMO, Rosa. A América Latina e sua criminologia. Rio de Janeiro: Revan, 2004.

DUSSEL, Enrique. 1492: o encobrimento do outro (A origem do "mito da modernidade"). Tradução: Jaime A. Clasen. Petrópolis: Vozes, 1993.

FIGUEIREDO, José Burle de. A contravenção de vadiagem. Rio de Janeiro: [s.n.], 1924.

FOUCAULT, Michel. História da sexualidade I: a vontade de saber. 13. ed. Rio de Janeiro: Graal, 1988.

. Em defesa da sociedade. São Paulo: Martins Fontes, 2005.

Vigiar e punir. 35. ed. Petrópolis: Vozes, 2008.

A verdade e as formas jurídicas. Rio de Janeiro: Nau Editora, 2009.

Os anormais. São Paulo: Martins Fontes, 2013

GARZONI, Lerice de Castro. Nas fronteiras do não-trabalho: trabalhadores pobres e as definições de vadiagem no início do século XX. Revista Mundo do Trabalho, v. 1, p. 65-95, 2009.

INSTITUTO BRASILEIRO DE GEOGRAFIA E ESTATÍSTICA (IBGE). Estatísticas do século $X X$. Disponível em: <http://seculoxx.ibge.gov. $\mathrm{br} /$ populacionais-sociais-politicas-e-culturais $>$. Acesso em: 19 set. 2014

KOERNER, Andrei. Punição, disciplina e pensamento penal no Brasil do século XIX. Lua Nova, n. 68, p. 205-242, 2006.

RAGO, Margareth. Do cabaré ao lar: a utopia da

${ }^{36}$ DUSSEL, Enrique. 1492: o encobrimento do outro (A origem do "mito da modernidade"). 
cidade disciplinar e a resistência anarquista. 4 . ed. São Paulo, Rio de Janeiro: Paz e Terra, 2014.

RODRIGUES, Raymundo Nina. As raças e a responsabilidade penal no Brazil. Rio de Janeiro: Guanabara, 1894.

SANTOS, Myriam Sepúlveda. A prisão dos ébrios, capoeiras e vagabundos no início da Era Republicana. Topoi, v. 5, n. 8, p. 138-169, jan.-jun. 2004.

SIQUEIRA, Geraldino. Direito penal brasileiro. Brasília: Senado Federal, Conselho Editorial, 2003. v. 2.

SOARES, Oscar Macedo. [1910] Código Penal da República dos Estados Unidos do Brasil comentado. Brasília: Senado Federal, Superior Tribunal de Justiça, 2004. v. 6. (Coleção História do Direito).

WEBER, Max. Ensaios de sociologia. Rio de Janeiro: Zahar, 1963.

ZAFFARONI, Eugênio Raul. Criminologia: Aproximación desde un margen. Bogotá: Edito-rial Themis, 1988. 